\title{
Articulaciones y problemas de la propiedad según Hegel ${ }^{*}$
}

\author{
Enzo Solari \\ Pontificia Universidad Católica de Valparaíso \\ enzo.solari@pucv.cl \\ https://orcid.org/0000-0002-5713-761X
}

\begin{abstract}
Resumen: La teoría hegeliana de la propiedad según emerge en el derecho abstracto de la persona tal como es diseñado en la Filosofía del Derecho afirma (a) que la propiedad es la objetivación externa de la voluntad libre mediante la apropiación (común o privada) de cosas exteriores, (b) que la propiedad no solamente mienta un mundo dado ya de antemano y al cual está referido el agente de praxis, sino también la diferencia absoluta entre personas y cosas y el problema protoeconómico del acceso de aquellas a estas mediante actos, (c) que la propiedad racionalmente necesaria para la libre personalidad supone el reconocimiento entre las autoconciencias (y esto aun cuando la noción de reconocimiento y de espíritu objetivo sean construcciones mejorables con una detalladísima analítica descriptiva tanto filosófica como empírica), y (d) que la propiedad, sin rechazar el formalismo típico del derecho privado, también exige la concreta universalidad del derecho público, un acceso a la misma por parte de todos y cada cual, y su organización y distribución universal a través de mecanismos institucionales y estatales.
\end{abstract}

Palabras clave: propiedad; libertad; espíritu objetivo; fenomenologia; justicia distributiva

\begin{abstract}
Joints and Problems of Property according to Hegel". Hegel's theory of property according to the person's abstract law in his Philosophy of Law states (a) that property is the external objectification of free will through appropriation (common or private) of exterior things; (b) that property does not only refer to a previously given world, but also to the absolute difference between persons and things and to the proto-economic problem of the persons' access to things through their actions; (c) that the property that is rationally necessary for the free personhood supposes the recognition between self-consciousness (even so the notions of recognition and objective spirit be improvable constructions with a detailed analytics both philosophical and empirical); and (d) that property, without refusing the typical formalism of private law, demands the concrete universality of public law, as also its access by all and each one, and its organization and universal distribution by means of institutional and governmental mechanisms.
\end{abstract}

Keywords: property; freedom; objective spirit; phenomenology; distributive justice

\footnotetext{
" Una versión preliminar de este texto se presentó y discutió con los participantes del Workshop sobre la filosofia práctica de Hegel celebrado en la Pontificia Universidad Católica de Valparaíso en abril de 2019, y la misma, tal como esta versión final, se enmarcan en el Proyecto Fondecyt Regular $\mathrm{n}^{\circ} 1180584$, del que es investigador responsable el autor.
} 


\section{Introducción}

En la primera parte de sus Grundlinien der Philosophie des Rechts $(F D)$, de $1820^{1}$, Hegel delinea un derecho abstracto y formal de la personalidad y presenta a la propiedad como la constitución de una esfera externa para la libertad y eo ipso como una objetivación de la persona mediante la apropiación volitiva de cosas exteriores. Tal es la primera exposición hegeliana de la propiedad. Estas líneas están dedicadas a desarrollar la argumentación de Hegel y luego a apreciar algunas de sus articulaciones más dificiles y problemáticas cuando se trasciende el plano estrictamente abstracto o formal.

\section{I.}

Hegel prepara su concepto de propiedad en la FD. Si se considera su ejecución más próxima, diría que al menos hay dos series de lugares imprescindibles. Primero, los §§34-36 acometen algo de rigor: la precisión de la persona como voluntad libre y del imperativo jurídico. El §34 entrega una noción inmediata de voluntad libre en el sentido de "la voluntad en sí individual de un sujeto (in sich einzelner Wille eines Subjects)" que niega la realidad y solo se relaciona consigo misma. El §35 ofrece una definición de persona o de personalidad, en la cual se destaca que ella es "una simple relación conmigo mismo (schlechthin reine Beziehung auf mich bin)", una finitud que se conoce a sí misma "como lo libre, lo general y lo infinito (in der Endlichkeit... so als das Unendliche, Allgemeine und Freye)". Persona, dice Hegel en la Anmerkung respectiva, es "el espíritu como un yo abstracto y precisamente libre". Y, en un Zusatz de Hotho, dice Hegel que persona es la voluntad abstracta o para sí, es un sujeto consciente de su libertad como un muy particular "esto": "la persona es al mismo tiempo lo sublime y lo más ordinario..., la unión de lo finito y lo infinito..., es la grandeza

\footnotetext{
1 El texto original es el de Hegel, G.W.F., Naturrecht und Staatswissenschaft im Grundrisse. Grundlinien der Philosophie des Rechts, en : Grotsch, K. y E. Weisser-Lohmann (eds.), Gesammelte Werke XIV, Hamburgo : Meiner, 2009. Uso libremente las versiones castellanas de E. Vásquez, Rasgos fundamentales de la filosofía del derecho o compendio de derecho natural y ciencia del estado, Madrid: Biblioteca Nueva, 2000); de Paredes, M. del C.: Líneas fundamentales de la filosofia del derecho, en Hegel II, Madrid: Gredos, 2010, pp. 9-312; de Vermal, J.L., Principios de la filosofía del derecho, Barcelona: Edhasa, 1988; y de Abellán, J., Fundamentos de la Filosofía del Derecho o Compendio de Derecho Natural y Ciencia Politica, Madrid: Tecnos, 2017); modificándolas aquí y allá.
} 
de la persona la que es capaz de sostener esta contradicción, la cual no tiene nada natural en ella misma ni podría soportarlo”. El §36, a su turno, dice que la capacidad jurídica es el atributo de la personalidad y que esta es el concepto y el fundamento del derecho abstracto y por lo mismo formal. Todo lo cual se sintetiza en el imperativo jurídico (Rechtsgebot): "sé una persona y respeta a los otros como personas (sey eine Person und respectire die andern als Personen)".

A continuación, los $\S \S 33$ y 40 muestran tanto las grandes divisiones de este libro (derecho abstracto, moralidad, eticidad, y, en esta, familia, sociedad civil y Estado) como las del derecho abstracto (propiedad, contrato, delito y pena). Según el §33, el derecho abstracto es una de las fases del desarrollo (Stufengange der Entwicklung) de la idea de voluntad libre en sí y para sí (die Idee des an und für sich freyen Willen). La propiedad (Eigenthum) se enmarca, dice Hegel, en la voluntad inmediata (der unmittelbare Wille), cuyo concepto abstracto es la personalidad (Persönlichkeit) y cuya existencia (Daseyn) es una cosa inmediata y exterior (eine unmittelbare äusserliche Sache). Esta es, a su modo de ver, la esfera del derecho abstracto, la que hay que distinguir-aunque no separar- de las esferas de la moralidad y de la eticidad o vida ética ${ }^{2}$. Su característica abstracción o formalidad, añade Hegel en la Anmerkung, no es otra cosa que la forma de la inmediatez o del ser (die Gestalt der Unmittelbarkeit oder des Seyns), que consiste en que una cosa o un contenido solo sea puesto según su concepto, es decir, según es en sí (an sich). En esta misma forma de la abstracta inmediatez del derecho puramente formal están, junto a

2 El derecho abstracto y formal, del que se trata en el §487 Enz, es, según la nota al §502 Enz, el derecho tradicional e inapropiadamente llamado natural. Véase Valls Plana, R., Comentario integral a la Enciclopedia de las ciencias filosóficas de G.W.F. Hegel (1830), Madrid: Abada, 2018, pp. 543-544. Comenta Ritter que Hegel se parapeta contra el iusnaturalismo de Wolff y la Escuela, contra el pensamiento (de una razón pura) de un derecho natural inmediatamente derivado de la naturaleza humana y que se diferencia de, y a la vez fundamenta a, todo derecho positivamente ordenado ( $C f$. Ritter, J., "Persona y propiedad. Un comentario de los §§34-81 de los "Principios de la Filosofia del Derecho' de Hegel”, en: Amengual, G. (ed.), Estudios sobre la "Filosofia del Derecho" de Hegel, Madrid: CEC, 1989, p. 123). En vez de ello, continúa Ritter, Hegel aboga por la libertad no separada de la realidad, sino convertida históricamente en "sustancia y determinación" (§4), o en "concepto" del derecho positivo (§1), o en el "reino de la libertad realizada" (§4; Cf. §31). De ahí la impotencia de la Restauración (véase lo que dice Hegel en Verhandlungen in der Versammlung der Landstände des Königsreiches Württemberg im Jahre 1815 und 1816, en: GW VI, p. 395) y la necesidad de trascender el iusnaturalismo abstracto "que se limita al 'en sí' o al ser natural e inmediato" (Ritter, J., "Persona y propiedad. Un comentario de los §§34-81 de los 'Principios de la Filosofia del Derecho' de Hegel”, pp. 127-129). Acerca del desarrollo de la expresión "derecho natural" en Hegel desde el texto dedicado al mismo de 1802-1803 hasta la $F D$, que ya es otro asunto, véase Bourgeois, B., Le droit naturel de Hegel (1802-1803). Commentaire, París: Vrin, 1986, pp. 634-639 ; y Eyssidieux-Vaissermann, A., "La refondation du droit naturel moderne", en: Kervégan, J.-F. y G. Marmasse (eds.), Hegel penseur du droit, París : CNRS Éditions, 2004, pp. 47-62. 
la propiedad, tanto el contrato como el delito y la pena. Esto lo agrega Hegel de acuerdo con los apuntes de Hotho, según los cuales además la voluntad libre tiene que darse existencia real a través de las cosas exteriores, lo que es tanto como decir que la persona -el sujeto concretamente libre para sí mismo- se da existencia en las cosas.

A su vez, el $\S 40$ repite los contenidos básicos del derecho abstracto: propiedad, contrato, delito y pena. Allí Hegel parte declarando que el derecho "es primeramente la existencia inmediata que se da la libertad (ist zuerst das unmittelbare Daseyn, welches sich die Freyheit auf unmittelbare Weise gibt)". Ya se distingue en este lugar entre posesión (Besitz) y propiedad, diciendo que esa existencia inmediata de la voluntad libre es ante todo "la posesión que es propiedad (Besitz, welcher Eigenthum ist)". Así concebida, la propiedad se dice de la persona individual "que solo se conduce consigo misma (sich nur zu sich verhaltenden Person)" y que por tanto es libre en el sentido de la voluntad abstracta en general (abstracter Wille überhaupt). Esto diferencia a la propiedad del contrato (Vertrag), donde ya está en juego la libertad de dos o más personas que son propietarios, y la diferencia también del injusto y el delito (Unrecht und Verbrechen), donde a su vez una voluntad particular (besonderer Wille) se diferencia y opone a la voluntad que es en sí y para sí. En la Anmerkung, Hegel discute con Kant y su división entre derechos de cosas, derechos de personas y derechos de personas de carácter real. Cree que Kant se equivoca al no distinguir entre derechos de la mera personalidad abstracta y derechos en cambio que presuponen situaciones sustanciales y éticas, como la familia o el Estado. Dice Hegel que "solo la personalidad da un derecho a cosas (ein Recht an Sachen) y que, por eso, el derecho personal es esencialmente derecho de cosas (und daher das persönliche Recht wesentlich Sachenrecht ist)", todo lo cual supone que la cosa "es en general exterior a la libertad (als das der Freyheit überhaupt Aeusserliche), en lo que se cuenta a mi cuerpo o mi vida (wozu auch mein Körper, mein Leben gehört)". Asi, hay que tratar primero el derecho general de la personalidad, al cual precisamente corresponde la propiedad también general, formal o abstractamente, y solo después "el derecho de la persona particularmente determinada (das Recht der besonders bestimmten Person)". A lo que se podría agregar que solo entonces pueden abordarse las particularidades que determinan inexorablemente a la propiedad ${ }^{3}$.

\footnotetext{
3 Ritter subraya que la persona y la propiedad del derecho abstracto son las del derecho privado romano: “...Hegel limita la teoría de la propiedad a la relación de personas a través de cosas establecida en el Derecho privado [romano]" (Ritter, J., "Persona y propiedad. Un comentario de los
} 
II.

Nótese que todo esto es solo una preparación para la conceptuación de la propiedad que se desenvuelve en los \$§41-71. Dicha conceptuación no descansa tanto en las (por otra parte importantes) determinaciones precisas de la enajenación (Entäusserung) de la propiedad, del uso (Gebrauch) y valor (Werth) de las cosas y de la misma posesión (Besitznahme) (§§53-70).Tampoco en las cuestiones (en otro contexto también decisivas) sobre la persona, la voluntad y el cuerpo (cuya inviolabilidad es para Hegel parte del derecho a la posible propiedad: $\S \S 47-48)^{4}$. Mucho menos en aquellas tesis (indispensables de tratar en otra oportunidad) sobre la primera ocupación (§50) ${ }^{5}$ y la toma de posesión (Besitzergreifung, §§51-52). Descansa, más bien, en el curso básico o elemental del argumento hegeliano acerca de la posibilidad de la propiedad, el que se halla sobre todo -si bien no solamente- en los §§41-46.

El §41 correlaciona a la persona con una esfera externa para su libertad (eine äussere Sphäre ihrer Freyheit) ${ }^{6}$. Dice Hegel que la persona se tiene que

§§34-81 de los 'Principios de la Filosofia del Derecho' de Hegel”, p. 122 (también p. 129)). Se trata del Derecho de Roma, pero puesto a la altura de los tiempos modernos (Cf. ibid., pp. 125-126 y 129), "con la revolución política y con el surgimiento de la sociedad civil", esto es, con la sustancia del mundo actual, lo que implica que la persona ya no designará más a una categoria particular de seres humanos, sino a todos ellos, con lo cual “...la libertad se eleva sin limitaciones al rango de principio y concepto del derecho” (Ibid., p. 127. Ritter remite al §209). La culminación de la historia universal de la libertad comenzada en Grecia es la libertad como realidad objetiva para todo ser humano (Cf. ibid., pp. 127-128): "partiendo del Derecho romano como base del Derecho civil, e interpretándolo a partir del fundamento de la libertad, la Filosofia del Derecho puede comprenderse como la teoría filosófica de la realización de la libertad en la existencia actual de todos como seres libres" (Ibid., p. 128). Por supuesto, Roma no es la única fuente de la teoría hegeliana de la propiedad, para la cual ha de considerarse también a Grecia - y a la idea del derecho como libertad(Ibid., p. 123) y al cristianismo, pues “...con la propiedad burguesa accede a la existencia la libertad cristiana” (Ibid., p. 131). Ritter dice, además, que “... para Hegel la revolución de 1789 está en conexión histórica e interna con la Reforma dentro de la historia de la libertad cristiana de todos" (Ibid., p. 138, n. 11). Por eso, agrega Ritter apologéticamente: "frente a la idea firmada durante casi un siglo de que su filosofia violenta al individuo y su libertad y lo sacrifica a la omnipotencia del Estado, solo en los últimos años se ha vuelto a comprender la posición central que ocupan la individualidad y su libertad subjetiva en la filosofia de Hegel" (Ibid., p. 138, n. 11; véase p. 140).

Sobre la apropiación del cuerpo, tema importante pero que debe relegarse para otra ocasión por sus diferencias con la apropiación de las cosas exteriores en general, véase Waldron, J., The Right to Private Property, Oxford: Oxford University Press, 1988, pp. 355, 360-363 y 370-377; Xifaras, M., "L’individualisme possessif, spéculatif (et néanmoins romain) de Hegel. Quelques remarques sur la théorie hégélienne de la propriété", en: Kervégan, J.-F. y G. Marmasse (eds.), Hegel penseur du droit, París: CNRS Éditions, 2004, pp. 63-79; Cordua, C., "El cuerpo propio", en: Estudios sobre Hegel, Santiago de Chile: Ediciones UDP, 2019, pp. 45-54.

5 Cf. Waldron, J., Private Property, pp. 386-389.

6 Esta idea según la cual el derecho de propiedad implica una esfera externa para el ejercicio de la libertad de cada persona proviene directamente de Fichte. Al respecto, cf. Wood, A., Hegel's Ethical Thought, Cambridge: Cambridge University Press, 1990, p. 95. 
dar esa esfera (muss... geben), y que tal esfera es algo diferente, distinto y separable de la voluntad infinita que es en y para sí y cuya primera determinación enteramente abstracta es la persona. Un Zusatz de Hotho subraya que la racionalidad de la propiedad no depende de la satisfacción de necesidades, sino de la superación (Aufhebung) de la mera subjetividad personal. Incluso afirma que "solo en la propiedad la persona es razón" y también que una cosa exterior otorga solo una primera (y mala) realidad a la libertad de la persona, pese a lo cual "no puede tener otra existencia que en la determinación de la inmediatez" mediante tal cosa en propiedad.

El $\S 42$ asevera que esa esfera externa del propio espíritu libre es "lo inmediatamente distinto [das unmittelbar Verschiedene]", es decir, que eso es para tal voluntad libre "en si lo exterior en general [an sich und das Aeusserliche überhaupt] -una cosa, algo sin libertad, no personal, sin derechos [eine Sache, ein unfreyes, unpersönliches und rechtloses]". "Cosa" aquí significa no lo sustancial, sino lo opuesto a lo sustancial: la determinación conceptual de la naturaleza (die Begriffsbestimmung der Natur) es ser lo exterior en y para sí. En Zusatz de Hotho, Hegel añade que la cosa es lo exterior incluso para ella misma (así, tiempo y espacio son exteriores, y yo mismo soy exterior: "como ser sensible, exterior, espacial y temporal"). También dice que las intuiciones sensibles son "de algo que es exterior él mismo" y que el animal puede intuir, pero que "el alma del animal no tiene como objeto su alma, no se tiene como objeto a sí mismo", sino solamente a lo exterior.

E1 §43 prolonga esta distinción entre persona y cosa, pues trata la existencia natural de la persona, tanto como concepto inmediato como en su esencial individualidad, diciendo que esa existencia en parte está en ella misma y en parte es algo con lo cual la persona se relaciona como con un mundo exterior. En la larga Anmerkung, se agrega que pueden llegar a ser jurídicamente posesiones o cosas incluso las habilidades intelectuales del arte, la ciencia y la religión, en el sentido de que a propósito de ellos cabe negociar, contratar y hasta enajenar, pese a que "son, sin duda, algo propio del espíritu libre, es decir, son algo interior y no exterior a él”. Esto es lo que confunde al entendimiento porque este piensa que algo es cosa o no es cosa, y por ende que lo que no es cosa no puede ser tratado nunca como cosa. Un ejemplo de esta confusión lo brinda el derecho romano, en la medida en que tomaba a los hijos como cosas para el padre -inmoral y antijurídicamente, aclara Hegel-y al mismo tiempo no podía menos que admitir que entre padre e hijos hay una "relación ética de amor", todo lo cual implicaba al cabo "una unión completamente injusta 
de ambas calificaciones: ser cosa y no ser cosa". El derecho abstracto trata de la persona y de los objetos distintos y separables de ella que pueden ser sus posesiones juridicas, siendo las habilidades espirituales posibles posesiones jurídicas (Hegel posterga para otro tratamiento posterior tanto el cuerpo como las propiedades interiores del espíritu adquiridas mediante educación, estudio, costumbres, etcétera).

El §44 afirma que hay un "derecho absoluto del ser humano a apropiarse cualquier cosa (absolutes Zueignungsrecht des Menschen auf alle Sachen)". En su virtud, la persona tiene el derecho a poner (legen) su voluntad en cualquier cosa, la cual se convierte en suya y adquiere así con esa voluntad un fin sustancial que antes no tenía, porque una cosa es algo precisamente sin un fin propio que sea su alma o su determinación ${ }^{7}$. Hegel suscribe en este lugar una forma de idealismo, aquella según la cual la apariencia de independencia (Schein von Selbständigkeit) que tienen las cosas para la conciencia, la intuición sensible y la imaginación, es por el contrario y según la verdad de semejante efectiva realidad (Wahrheit solcher Wirklichkeit), la voluntad libre del idealismo (der freye Wille der Idealismus). Aquella independencia es refutada, en efecto, por la actitud de la voluntad libre ante las cosas individuales inmediatas. Hotho, en el Zusatz, desarrolla la misma tesis, arguyendo que el idealismo es la voluntad libre que "no toma a las cosas como son por cosas en sí y para sî", mientras que el realismo absolutiza a las cosas, aun cuando solo sean finitas. Incluso los animales no humanos, que (como los demás seres vivos) son cosas exteriores, al consumir otras cosas demuestran con su conducta que estas no son independientes ni absolutas. Al no tener una cosa fin propio en tanto es siempre y solo algo finito, relativo y exterior (aun a sí mismo), hay, pues, un derecho a convertir la voluntad libre (infinita, absoluta e interior) en cosa o a esta en su voluntad, o sea, un "derecho a superar (aufheben) la cosa y convertirla en una de las suyas".

El §45 define posesión y propiedad, conceptos que ya había distinguido en el §40. Posesión (Besitz) radica en tener algo en mi poder externo (Ich habe etwas in meiner selbst äussern Gewalt), tal como cuando hago mío algo por necesidades naturales, impulsos y arbitrio, esto es, por mi interés particular

\footnotetext{
7 Comenta Ilting que este derecho absoluto de apropiación no se debe a que "todas las cosas puedan servir a la satisfacción de las necesidades humanas, sino porque el hombre, declarando así una cosa como de su propiedad, se crea el presupuesto de la acción libre en el mundo" (Ilting, K.-H., "La estructura de la 'Filosofia del Derecho' de Hegel", en: Amengual, G. (ed.), Estudios, p. 71$)$.
} 
(das besondere Interesse). Propiedad (Eigenthum), a su vez, es la otra cara, la de objetivarme a mí mismo como voluntad libre en la posesión y ser así una voluntad efectivamente real (Ich bin als freyer Wille mir im Besitze gegenständlich und hiemit auch erst wirklicher Wille). Esto constituye lo verdadero y jurídico (das Wahrhafte und Rechtliche) en la determinación de la propiedad (die Bestimmung des Eigenthums) ${ }^{8}$.

El §46 importa, más que por algunas consideraciones algo detalladas sobre la distinción entre propiedad común y propiedad privada, porque reafirma que mi voluntad personal e individual se vuelve voluntad objetiva en la propiedad y que, por ende, esta reclama el carácter de posible propiedad privada (Privateigenthum), sin que ello excluya la posibilidad de la propiedad común (gemeinschaftliches Eigenthum). La Anmerkung documenta esto más precisamente en el derecho romano y a través de la propiedad familiar fideicomisaria, de donde puede extraerse que el derecho a la propiedad privada tiene un vínculo íntimo con el derecho de la personalidad. Añade Hegel aquí que las determinaciones específicas (o excepciones, Ausnahmen) de la propiedad privada pueden tener que fundarse no en meros intereses privados, sino en la comunidad, en el Estado ("en el organismo racional del Estado (in dem vernünftigen Organismus des Staats") como esfera superior del derecho (höhern Sphären des Rechts). Hegel critica al Estado platónico por poco respetuoso de la propiedad privada en general, lo que es, según Hegel, "una injusticia contra la persona (das Unrecht gegen die Person)", un desconocimiento de la libertad del espíritu y del derecho, un no captar sus momentos determinados (de lo que hasta Epicuro se habria dado cuenta; Hegel cita a Diógenes Laercio, 1, X, 6). En Zusatz de Hotho, junto con repetir que solo el Estado puede hacer excepciones a la propiedad privada, Hegel muestra el tránsito desde la voluntad -que es siempre de alguien- hasta la característica de la propiedad según la cual ella se verifica siempre (como en una necesidad racional) en un "esto es mío". Hegel dice que "esta es la importante doctrina de la necesidad de la propiedad privada", o, como dirá en el §49, "en relación con las cosas exteriores, lo racional es que yo posea propiedad (im Verhältnisse zu äusserlichen Dingen ist das Vernünftige, dass Ich Eigenthum besitze)".

\footnotetext{
8 Anmerkung: si desde el punto de vista natural de las necesidades la propiedad es un medio (Mittel), en cambio desde el punto de vista de la libertad (die Freyheit) es la primera existencia de ella misma (das erste Daseyn derselben), es fin esencial para sí (wesentlicher Zweck).
} 
III.

Así pues, una sintesis de la teoría hegeliana de la propiedad -según el derecho abstracto de la persona tal como es diseñado en la $F D$ - ha de incluir cuando menos estas tesis ${ }^{9}$ : (i) la de la persona como voluntad libre y la del imperativo jurídico de ser persona y respetar la personalidad ajena, (ii) la idea de la voluntad libre en sí y para sí y la del derecho como la existencia inmediata que se da la libertad y cuyas manifestaciones jurídicas más abstractas son la propiedad, el contrato, el delito y la pena (mientras que las más concretas y desarrolladas son la eticidad de la familia, la sociedad civil y el Estado), (iii) la comprensión de la propiedad como una vinculación racional de la persona con una esfera externa para su libertad y también de que una cosa exterior otorga realidad solo primera a la libertad de la persona, (iv) que esa esfera externa del propio espíritu libre es algo inmediatamente distinto (una cosa sin libertad ni personalidad ni derechos), (v) que la existencia natural de la persona en parte está en ella y en parte es para ella un mundo exterior, (vi) que hay un derecho absoluto de la persona a apropiarse cualquier cosa (y a poner su voluntad en la misma cosa haciéndola suya), (vii) que la jurídica determinación de la propiedad consiste en que cada voluntad libre es para sí objetivamente en la posesión y que de ello pende que sea voluntad efectivamente real, y en fin (viii) que la voluntad personal e individual al volverse objetiva mediante la propiedad reclama la apropiabilidad privada (sin excluir la comunidad).

Con todo, esta teoria hegeliana de la propiedad in abstracto no deja de plantear otras cuestiones filosóficas y jurídicas que ayudan a perfilar el estatuto de la propiedad según Hegel. Algunas de estas cuestiones son fenomenológicas, por ejemplo, qué fenomenología y qué tipo de inmediatez considera Hegel respecto de las personas, las cosas y la propiedad -y a cuál otra cabría recurrir- para entender afirmaciones como las suyas: que es la voluntad libre del individuo abstracto sin más la que porta la titularidad de la propiedad, y que, por ende, las cosas son exterioridades apersonales que se resisten a su actuar libre en el contexto de un mundo ya dado de antemano. Otras cuestiones no son puramente fenomenológicas, sino de índole ontológica-social o política. Por ejemplo: ¿se ha desatado ya el reconocimiento cuando de la libertad y de las cosas apropiables se trata? ¿Se tratan en algún momento posterior -en teorías fuertemente explicativas y que a Hegel no le interesan al nivel del derecho

9 Varias de las cuales reaparecerán de manera condensada, aunque con algunos cambios, en Enz $\S \S 488-492$. 
abstracto- las particularidades públicas y políticas de la propiedad del tipo qué y cuánto (y podría agregarse cómo) posee alguien?

IV.

En primer lugar deben examinarse ciertas consideraciones fenomenológicas de Hegel, precisamente en el sentido de una investigación de los fenómenos, de lo que aparece en tanto que aparece, esto es, de una filosofia primera. Una de ellas es la del §34 ya mencionado, que muestra cómo es que la voluntad individual libre no es autorreferente, puesto que tiene "simultáneamente ante sí un mundo exterior, inmediato y previo (zugleich... eine äussere, unmittelbar vorgefundene Welt vor sich)". Esta idea se repite en el §39, cuando se menciona que la individualidad personal se conduce por una naturaleza previamente dada y a la que se opone como algo subjetivo ${ }^{10}$. Luego de ello, y tratando de la toma de posesión (Besitzergreifung), el §52 dice que "la materia no es para sí propia de ella (die Materie ist für sich nicht ihr eigen)". Hegel añade fenomenológicamente en la Anmerkung respectiva que "la materia me ofrece resistencia (leistet mir Widerstand)" y que en eso consiste la materia y en nada más. Al explicar y no simplemente describir esto, Hegel afirma que se trata de un choque de abstractos: la materia mostrando su abstracto ser para sí (abstractes Fürsichseyn) a una voluntad como espiritu abstracto, es decir, como espíritu sensible ("la percepción sensible toma erróneamente el ser sensible del espíritu por lo concreto y toma lo racional por lo abstracto"). Desde el punto de vista de la voluntad y la propiedad, este ser para sí de la materia no tiene verdad. Según el añadido de Griesheim al §55, Hegel piensa el contacto físico entre sujeto poseedor y cosa poseída como uno gracias al cual solo se entra a poseer lo que se ha tocado con el propio cuerpo, peculiarmente con las manos ("la mano es ese gran órgano que no tiene animal alguno..."). Sin embargo lo que se empieza a poseer asi puede ampliarse a otras cosas distintas pero relacionadas con la inicialmente apropiada. Esto ocurre según lo regule positivamente el derecho: “...y lo que aprehendo con ella [la mano, aunque de consuno con cierta inferencia que es obra del entendimiento] puede

\footnotetext{
${ }^{10}$ ¿Huellas del Lebenswelt de Husserl? Por una respuesta afirmativa, incluyendo la referencia a las cosas inmediatas y al mundo exterior de la persona incluso abstractamente considerada que hace el §43, cf. Mohseni, A., "Eigentum und die soziale Sichtbarkeit der Person", en: L. Siep (ed.), G. W. F. Hegel. Grundlinien der Philosophie des Rechts, Berlin/Boston : Walter de Gruyter, 2017, pp. 64-65.
} 
llegar a ser un medio con el que aprehendo más aún... El derecho positivo tiene que hacer aquí sus estipulaciones, pues nada más puede derivarse del concepto”. El §64 introduce, junto a la coordenada espacial ya expuesta, la del tiempo, diciendo que "la presencia subjetiva de la voluntad (die subjective Gegenwart des Willens)" y “...[que] el uso, la utilización o cualquier exteriorización de la voluntad" requieren tiempo, como si dijera que el ser (de la cosa poseída) es tiempo (es voluntad que dura). La voluntad de posesión solo tiene realidad efectiva si existe y persiste o, en palabras de Hegel, si "ocurre en el tiempo (fällt in die Zeit), respecto al cual la objetividad es la duración de esta exteriorización (die Objectivität ist die Fortdauer dieses Aeusserns). Sin ella, la cosa, en cuanto abandonada por la realidad de la voluntad y de la posesión, queda sin dueño (herrenlos). Por consiguiente, pierdo o adquiero propiedad mediante prescripción (durch Verjährung)".

Estas consideraciones hegelianas de carácter fenomenológico han de ser enmarcadas en la $F D$. En esta obra Hegel supone -y recurre explícita y también implícitamente a- las tesis y la concepción filosófica de la Ciencia de la lógica: “...tanto la totalidad como el desarrollo de sus miembros [en $F D$ ] descansan en el espíritu lógico. Quisiera particularmente que este manual fuera concebido y juzgado desde ese aspecto (das Ganze wie die Ausbildung seiner Glieder beruht auf dem logischen Geiste. Von dieser Seite möchte ich auch vornemlich, dass diese Abhandlung gefasst und beurtheilt würde)" (Vorrede).

Esto implica asumir la pretensión de arrancar sin presuposiciones en uno y otro caso -mutatis mutandis, por cierto, según los temas de cada obra-. Dado que Hegel argumenta profusamente esto, bastarán solo algunas alusiones que brinda la primera edición del tratamiento del ser de 1812 acerca de dicha metodología fenomenológica (esto en el sentido del ideal filosófico de la ausencia de presuposiciones o, dicho de otra manera, del examen más radical que sea posible de las mismas, lo que equivale a conceder que esta pretensión es tan ineludible como imposible): "en ninguna ciencia se siente más fuertemente que en la ciencia de la lógica la necesidad de hacer el inicio por la cosa misma, sin reflexiones preliminares (ohne vorangehende Reflexionen von der Sache selbst anzufangen) ...Contra lo que hacen las otras ciencias, la lógica no puede presuponer en cambio ninguna de estas formas de la reflexión o reglas y leyes del pensar (die Logik dagegen kann keine dieser Formen der Reflexion oder Regeln und Gesetze des Denkens voraussetzen), pues ellas constituyen una parte de su contenido, y tienen primero que ser fundamentadas en el interior... Igualmente su objeto, el pensar o, de un modo más determinado, el pensar 
concipiente, es tratado esencialmente dentro de ella; el concepto del mismo se engendra en el curso de esta, y por consiguiente no puede ser ofrecido de antemano (der Begriff desselben erzeugt sich in ihrem Verlaufe und kann somit nicht vorausgeschickt werden)" (Einleitung).

Asimismo, Hegel sostiene que: “...el inicio de la ciencia absoluta tiene que ser él mismo inicio absoluto; nada le está permitido presuponer. Por nada tiene que estar pues mediado, ni tener un fundamento; él mismo debe ser más bien el fundamento de la ciencia toda (der Anfang der absoluten Wissenschaft muss selbst absoluter Anfang seyn, er darf nichts voraussetzen. Er muss also durch nichts vermittelt seyn, noch einen Grund haben; er soll viemehr selbst der Grund der ganzen Wissenschaft seyn) ...El inicio es pues el ser puro (Der Anfang ist also das reine Seyn)" (Erstes Buch, das Seyn, inicio) ${ }^{11}$.

Ahora bien, tal pretensión fenomenológica se declinaría muy distintamente si se compara a Hegel con Husserl y sus continuadores. En efecto, con otra comprensión de la inmediatez Husserl distingue -a diferencia de Hegelentre la aparición, manifestación, donación, revelación intuitiva o experiencial del fenómeno y su vacía mención lingüística objetiva, lo que un husserliano de estricta observancia ha resumido como sigue: "los estados de cosas mentados en expresiones verbales nunca aparecen en virtud de los meros actos en que consiste la comprensión del significado. En los actos de habla y escucha, el correlato intencional no está presente en una imagen (ya que, por supuesto, no a la vista); la comprensión no tiene por qué asociarse con ninguna intuición distinta de la del correspondiente signo sonoro o gráfico. Y este último es enteramente convencional, arbitrario, no dibuja su objeto, lo significa. El carácter intrínsecamente no intuitivo de la mención lingüística no es por tanto un grado ulterior de debilitamiento de la intuición [como lo son el recuerdo, la anticipación y la imaginación respecto de la percepción...], sino una forma específica,

${ }^{11}$ En idéntica dirección, véase la caracterización que hace Houlgate del ideal filosófico según Hegel: "lo que terminó por convencerme de que había un verdadero mérito en el modo de pensar de Hegel fue su exigencia de ser tan escéptico y auto-crítico como fuera posible: nada podía darse por sentado... Tengo que admitir, por supuesto, que ser absolutamente auto-crítico y comenzar a filosofar sin ningún tipo de presuposición no necesariamente significa que uno terminará filosofando exactamente de la misma manera que lo hizo Hegel en todo respecto. Pero aun así me impresionó lo persuasivo y poderoso de este modo de aproximarse a la filosofia; y no podía aceptar la alternativa, porque esta suponía no querer ser crítico, querer tener presuposiciones, querer ser arbitrario. Aún hoy me sorprende que, si uno reconoce la fuerza de esta exigencia de no dar nada por sentado, de no aceptar nada porque sí, de no fundar lo que uno dice en presuposiciones arbitrarias, no hay ninguna otra forma de hacer filosofia" ( $C f$. Gottschlich, M., "Enseñando a hablar inglés a la filosofia hegeliana. Entrevista a Stephen Houlgate", en: Ideas y valores, Abramovich, L. (trad.), v. LXVI, 165 (2017), p. 378). 
distinta, de intencionalidad. Investigaciones lógicas [sobre todo la $1^{\mathrm{a}}$., caps. I y II, y la $6^{\mathrm{a}}$., sección I, caps. I-III] proponía como una primera caracterización esencial de las intenciones significativas la condición 'vacia' de la mención verbal. Esta apunta a su término objetivo, lo fija, lo describe, sin tomar nada 'vivo' del objeto; la identificación y descripción se trasmiten sin requerir una donación, ya sea precaria, del objeto. Lo sorprendente es que este carácter vacío de la mención lingüística en nada afecta a la determinación de la situación mentada. Bien mirado, ocurre exactamente lo contrario: la no-aparición confiere a las intenciones significativas una singular precisión... Y es que solo la articulación del sentido en hueco, 'en vacío', en signos dotados de significado, pero horros de la plenitud de la cosa, puede obrar este cotidiano prodigio de separar en la mención lo que en el objeto es inseparable"12.

Aun en fenomenologias recientes se aprecia que la respectividad o relación humana con las cosas exteriores -así como la misma institución de la propiedad-bien puede ser analizada despidiéndose del ser y su presunta inmediatez, sea que se haga de la realidad, de la vida o de la praxis, ese ámbito inmediato o de experiencia originaria. Todo radica en el modo de analizar

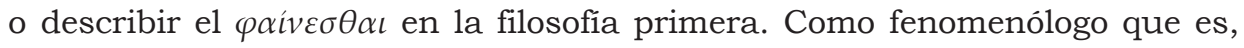
distinguiendo pues en la fenomenalidad o aparecer entre el aparecer mismo y aquello que aparece, González ha sugerido que la correcta distinción hegeliana entre personas y cosas está basada, según un análisis riguroso, en la distinción del surgir respecto de lo que en él surge. Esto sería como apropiarse (con alguna modificación) de una frase de Amengual: “...la persona se particulariza surgiendo de su subjetividad y empezándose a relacionar con cosas externas o con la exterioridad en general"13. En el preciso sentido de que la persona es el surgir o aparecer de cosas que surgen o aparecen, "lo personal no reside primeramente en un sujeto por detrás de los actos, sino que puede encontrarse en los actos mismos. La categoría más adecuada para lo personal no es, como suele pensar la filosofia occidental, el sujeto. Antes que el ser 'sujeto de' [à la manera moderna] y el 'estar sujeto a' [à la Levinas] tenemos el surgir mismo como carácter de los actos. Los actos, como actos, son en sí mismos esencialmente personales. En el surgir carnal, corpóreo, tenemos la esencia misma de lo personal. Por eso mismo el surgir de las cosas, el surgir de los entes, el surgir

\footnotetext{
${ }^{12}$ Serrano de Haro, A., Paseo filosófico en Madrid. Introducción a Husserl, Madrid: Trotta, 2016, pp. 61-62.

${ }_{13}$ Amengual, G., La moral como derecho. Estudio sobre la moralidad en la Filosofia del Derecho de Hegel, Madrid: Trotta, 2001, p. 90.
} 
del ser nunca es algo impersonal. Es algo que ni Heidegger mismo ni sus críticos supieron ver propiamente. La filosofia de los actos, la filosofia primera que no renuncia a ser análisis de los actos, la praxeología, no implica ni puede implicar en modo alguno un anti-humanismo. Y, sin embargo, la filosofia que se mantiene en el análisis de los actos no es un subjetivismo. Señalar que el sujeto está sujeto a otros, o sustituir la subjetividad 'monológica' de la modernidad por la 'intersubjetividad lingüísticamente mediada' [à la Habermas] no es una manera de superar la metafísica de la subjetividad. En todos los casos abandonamos los actos para trasladarnos hacia sus condiciones de posibilidad, hacia transcendencias de distinto tipo. La filosofia primera que se mantiene en el análisis radical de los actos encuentra lo personal no en el sujeto, sino en los actos mismos"14.

A la vez, González sugiere atender a esa primaria dimensión económica que exhiben los seres que intervenimos en las acciones de los demás y que recibimos la intervención de los demás en nuestras propias acciones, y siempre en relación con el acceso ajeno o propio a las cosas: "los demás intervienen en mi acción permitiéndome o impidiéndome el acceso a [...las cosas]. En este sentido, podemos decir que la presencia de los otros en mis acciones tiene una dimensión 'económica'. La socialidad de las propias acciones es 'económica' porque incluye la lucha por el acceso a las cosas"15.

Todo lo cual puede impactar en la teoria de la propiedad, pues en ella debiera reflejarse de alguna manera jurídicamente sofisticada y manejable la distinción entre personas y cosas -así como entre personas y entre cosas-, incluyendo por lo demás la dimensión económica del acceso personal a las cosas que tarde o temprano afectará -e introducirá el conflicto- no solo al régimen -privado y público- de las cosas sino también al estatuto -privado y público- de las personas ${ }^{16}$.

$160{ }^{14}$ González, A., Surgimiento. Hacia una ontología de la praxis, Bogotá: Universidad Santo Tomás, 2014, p. 259.

${ }^{15}$ González, A., Estructuras de la praxis. Ensayo de una filosofia primera, Madrid: Trotta, 1997, p. 98.

${ }^{16}$ Sobre esta dimensión económica y conflictiva de las cosas en relación con las personas y si Hegel algo entrevió de la misma al tratar de los mercados, véase Herzog, L., "Hegel als Denker des Marktes”, en: Siep, L. (ed.), G.W.F. Hegel. Grundlinien der Philosophie des Rechts, pp. 209-224; y Schmidt am Busch, H.-Ch., "Why Ethical Life is Fragile: Rights, Markets and States in Hegel's Philosophy of Right”, en: James, D. (ed.), Hegel's Elements of the Philosophy of Right. A Critical Guide, Cambridge: Cambridge University Press, 2017, pp. 137-159. 
V.

Ahora bien, hay unos argumentos ontológico-sociales y normativos sobre la propiedad que no conviene pasar por alto y que transcienden las anteriores consideraciones fenomenológicas, aunque podrian hallarse incoativamente en ellas (las de Hegel y más allá de él). Son, por supuesto, aquellos sobre el reconocimiento. El §57 trata la esclavitud desde el punto de vista del ser natural (Naturwesen) del hombre, tema tanto de este parágrafo como también del §43. De acuerdo con el Zusatz de Hotho al §57, la esclavitud no es compatible con la eticidad: "la esclavitud ocurre en el tránsito de la naturalidad del hombre a la situación verdaderamente ética: ocurre en un mundo en el que todavía es derecho una injusticia”. Sin embargo, Hegel tiene que decirlo todo, lo que aquí -en la Anmerkung al §57-implica que es unilateral y falso considerar la realidad inmediata de la esclavitud como justificación de la misma, pero a la vez que no hay que perder de vista que el mero concepto sin existencia de la libertad es un punto de partida absoluto, si bien no más que un punto de partida y por ende algo también unilateral. La idea es lo verdadero, dice Hegel, y esto significa que "el espíritu libre es precisamente esto...: no ser como el mero concepto o en sí (an sich), sino superar este formalismo de sí mismo y, de ese modo, a la existencia natural inmediata y darse la existencia solamente como la suya, como existencia libre". Por eso la esclavitud puede parecer aceptable y posible solo para la conciencia inmediata, pero ya no tras la dialéctica del concepto y la lucha del reconocimiento (der Kampf des Anerkennens) cuando se alcanza la libertad realizada, esto es, el Estado, puesto que "la idea de la libertad solo es verdaderamente como el Estado (die Idee der Freyheit ist wahrhaft nur als der Staat)"17.

En la Anmerkung al §62, Hegel contrapone el antiguo florecimiento de la libertad de la persona -mediante el cristianismo- con el reciente reconocimiento de la libertad de la propiedad: "la libertad de la propiedad ha sido reconocida (anerkannt) como principio aquí y allá, desde ayer (seit gestern, kann man sagen), por así decirlo"18. Su remate no tiene desperdicio: este es "un ejemplo

\footnotetext{
17 Sobre la esclavitud, la propiedad y el derecho abstracto, véase Wood, A., Hegel's Ethical Thought, pp. 96-99.

18 Por cierto, el nexo entre la libertad cristiana y la propiedad burguesa es destacado por Ritter: “...con la propiedad burguesa accede a la existencia la libertad cristiana... Para Hegel la revolución de 1789 está en conexión histórica e interna con la Reforma dentro de la historia de la libertad cristiana de todos" (Ritter, J., "Persona y propiedad. Un comentario de los $\$ \S 34-81$ de los 'Principios de la Filosofia del Derecho' de Hegel”, pp. 131 y 138, n. 11). Lo cual se prolonga en la sociedad civil mediante la propiedad y el trabajo: "este es para Hegel el sentido racional de
} 
de la historia universal sobre la extensión del tiempo que el espíritu requiere (über die Lange der Zeit, die der Geist braucht) para progresar en su autoconciencia (in seinem Selbstbwusstseyn fortzuschreinten) y contra la impaciencia del opinar (und gegen die Ungeduld des Meynens)".

En el $\S 71$, que es la bisagra o tránsito (Uebergang) entre la propiedad y el contrato, Hegel afirma que "la existencia (Daseyn), como ser determinado, es esencialmente ser para otro (wesentlich Seyn für anderes)". "Para otro" quiere decir que la existencia de la voluntad -y la propiedad es la primera manifestación de tal existencia- "es en cuanto para otro solo para la voluntad de otra persona (nur für den Willen einer andern Person)". Tanto así que "esta relación de voluntad a voluntad (diese Beziehung von Willen auf Willen) es el terreno apropiado y verdadero en el que la libertad tiene existencia (der eigentühmliche und wahrhafte Boden, in welchem die Freyheit Daseyn hat)". Entonces la propiedad se constituye en la esfera del contrato (die Sphäre des Vertrags). Pero hay más. En la Anmerkung (la cual termina remitiendo al §35 y a la arriba mencionada Anmerkung al §57) se subraya la función del reconocimiento: dice Hegel que es racionalmente necesario (y no algo necesario solo por la utilidad, el bienestar y las necesidades) que haya propiedad y contrato, pues es la razón ("la idea de la existencia real de la libre personalidad (die Idee des reellen... Daseyns der freyen Persönlichkei)]" que solo existe en la voluntad) la que lleva a una y otro. Hegel añade: “el contrato presupone que aquellos que comparecen en él se reconozcan como personas y propietarios (der Vertrag setz voraus, dass die darein tretenden sich als Personen und Eigenthümer anerkennen). Puesto que el contrato es una relación del espíritu objetivo, el momento del reconocimiento ya está contenido y presupuesto en él (das Moment der Anerkennung schon in ihm enthalten und vorausgesetzt)".

Así puede volverse al $\S 45$ de $F D$ y entender mejor la interpretación que hace del mismo Cordua: "tener algo externamente en mi poder constituye la posesión. La propiedad, en cambio, no depende del poder que yo pueda tener sino de ciertas relaciones sociales y jurídicas. La posesión tiene un aspecto particular que reside en el interés que me lleva a apoderarme de algo. Hago mias las cosas por necesidad natural, por impulso o porque me da la gana. Pero si tengo algo en cuanto soy no meramente persona abstracta sino voluntad libre, mi relación con la cosa cambia de carácter. Pues en cuanto propietario

las modernas relaciones laborales [donde ya no hay espacio para el amo y el esclavo]; con ellas se impone la libertad de todos, aunque en un primer momento en la forma de la miseria" (Ibid., p. 141, comentándose el §67). 
no soy ya un mero conjunto de apetitos e intereses arbitrarios sino miembro reconocido de una sociedad que se gobierna por leyes. Esta condición me da una objetividad que me faltaba antes: me reconozco en mi propiedad y, en este sentido, es mediante ella que soy, por primera vez, voluntad actual, efectiva. La voluntad que se objetiva supera su confinamiento en la mera subjetividad; por eso la propiedad representa una superación de la posesión, o la verdad de esta, y constituye una institución jurídica en vez de una mera relación de poder"19.

En efecto, no hay razones para pensar que el concepto de persona con que se abre el derecho abstracto estuviese desconectado del reconocimiento recíproco o intersubjetivo, sino que por el contrario las hay en el sentido de que el reconocimiento está presupuesto desde el inicio mismo de FD. En este sentido importan, por una parte, las menciones al reconocimiento que hacen más adelante los $\S \S 132$ y 260 de $F D$ y que permiten releer los parágrafos sobre la propiedad a una nueva luz, y por la otra, que en varios lugares de la obra hegeliana se argumenta explícitamente que en el derecho de la propiedad y la persona ya está operando el reconocimiento mutuo -así sucede antes en la Filosofía Real de $1805 / 6^{20}$ y después en la breve sección dedicada a la propiedad en la Enz el §490: "en la propiedad, la persona está concluida consigo (in dem Eigentum ist die Person mit sich selbst zusammengeschlossen). La cosa, empero, es abstractamente exterior, y yo en ella [soy también] abstractamente exterior. El regreso concreto de mí hasta mí en la exterioridad consiste en que yo (que soy la infinita referencia de mí a mí) soy como persona la repulsión de mí mismo por mí y en el ser de otras personas, de mi referencia a ellas y, en el ser reconocido por ellas que es así recíproco (dem Anerkanntsein von ihnen, das gegenseitig ist), tengo la existencia de mi personalidad (das Dasein meiner Persönlichkeit habe)"21.

Aunque la abstracción y formalidad del derecho a la apropiación en FD parezca ocultarlo, el movimiento del reconocimiento recorre el arco entero del

\footnotetext{
${ }^{19}$ Cordua, C., Explicación sucinta de la Filosofia del Derecho de Hegel, Bogotá: Temis, 1992, pp. 44-45. Las cursivas son mias.

${ }^{20}$ Cf. Hegel, G.W.F., GW VIII, p. 226-228.

${ }^{21}$ Comenta Valls (de quien es aquella traducción): "esta autorreferencia consiste en que yo, como persona propietaria, soy la infinita referencia de mí a mí, la cual incluye la repulsión de mí mismo y del ser de otras personas con su propia referencia a la cosa, pero incluye también el ser reconocido por las otras personas como otro propietario. Este reconocimiento resulta así recíproco, y yo tengo en esas personas la Ex-sistencia de mi personalidad igual que ellas la tienen en mí. Juntos formamos la comunidad de los señores (propietarios), básica para la Ex-sistencia ulterior de la comunidad universal de los humanos": Valls Plana, R., Comentario integral a la Enciclopedia de las ciencias filosóficas de G.W.F. Hegel (1830), p. 539.
} 


\section{derecho, incluidas en su fase abstracta y a fortiori también las posteriores ${ }^{22}$. Cuestión aparte, también fenomenológica, es si la versión que da Hegel del}

${ }^{22}$ El asunto es relativamente pacífico en la literatura secundaria. "Gegen die Deutung des Hegelschen Ausgangspunktes als 'Individualismus' oder FD, Wood ha 'Liberalismus' bzw. gegen die These von der 'verdrängten Intersubjektivität' [Theunissen] oder gegen die Behauptung, dass Hegel den 'Personenbegriff völlig von Intersubjektivität losgelöst denkt [Hösle], kann eingewendet werden, dass das Moment der Anerkennung im Hegelschen Anfang voraussgesetzt ist' (Vieweg, K., it Das Denken der Freiheit. Hegels Grundlinien der Philosophie des Rechts, Paderborn: Wilhelm Fink, 2012, pp. 102-103. Las cursivas son mias). De ahí que Vieweg -de la mano de Enz \$§436, 437 y 490- admita en el concepto abstracto de persona de la FD un específico reconocimiento de subjetividad o capacidad jurídica (pp. 96 y 102-103). Vieweg cita a Siep: “dass die prinzipielle Gleichheit aller Rechtssubjekte in Hegels Rechtsphilosophie nicht mehr eigens erörtert werden muss, liegt daran, dass in der Allgemeinheit des sich wissenden Wissens ein wechselseitiges Anerkennungsverhältnis impliziert ist" (Siep, L., "Intersubjektivität, Recht und Staat in Hegels Grundlinien der Philosophie des Rechts", en: Henrich, D. y R.P. Horstmann (eds.), Hegels Philosophie des Rechts. Die Theorie der Rechtsformen und ihre Logik, Stuttgart, 1984, p. 259. Las cursivas son mias. Siep, claro, también ha tratado esta cuestión en su conocida Habilitationsschrift: Anerkennung als Prinzip der praktischen Philosophie. Untersuchungen zu Hegels Jenaer Philosophie des Geistes, Hamburgo: Meiner, 2014, pp. 274-281). Amengual parece suscribir esta interpretación -especialmente en la versión que ofrece Siep discutiendo con Ilting- cuando dice que la persona, definida inmediatamente por su auto-relación y no por alguna relación intersubjetiva, sin embargo presupone la lucha por el reconocimiento ya acontecida en el espíritu subjetivo, de manera tal que toda relación de derecho es ya una relación de reconocimiento: Amengual, G.. La moral como derecho. Estudio sobre la moralidad en la Filosofía del Derecho de Hegel, pp. 75-78, 91-92 y 112. Y Houlgate se manifiesta en idéntico sentido, parafraseando la exigencia jurídica básica de respetar a los demás en tanto que personas del §36 como exigencia de mutuo reconocimiento; la estructura lógica de la persona como titular de derechos hace necesario tal reconocimiento de la misma libertad en todas las personas o, en sus palabras, de que "the sphere of right is that of mutual recognition between persons" (Houlgate, S., "Property, Use and Value in Hegel's Philosophy of Right", en: James, D., Hegel's Elements of the Philosophy of Right. A Critical Guide, p. 41). Por un lado, Houlgate remite también al $\S 436$ de la Enz, donde se muestra cómo es que el reconocimiento recíproco "is a logical precondition of all reason and spirit" (Ibid., p. 41); y por otro, precisa a continuación que el derecho precede y vuelve necesario el reconocimiento mutuo, sin estar aquel constituido por este, o sea, sin ser verdad que -como se ha dicho- el derecho se funde en el reconocimiento, sino más bien que el derecho es hecho necesario por el concepto de persona y, más que presuponer reconocimiento, exige que haya reconocimiento entre personas: p. 42. Lo mismo afirma a su manera W. Schild: el reconocimiento, no en el sentido de la autoconciencia que expone la Fenomenología del espiritu, sino aquel entre personas de la $F D$, es "das wirkliche Gersetz dieser Welt der Freiheit... 'El reino de la libertad efectivamente realizada, el mundo del espíritu surgido del espíritu mismo como una segunda naturaleza (das Reich der verwirklichten Freyheit, die Welt des Geistes aus ihm selbst hervorgebracht, als eine zweyte Natur, ist)' [que aparece en el $\S 4$ de la FD y al que Hegel llama sistema jurídico, Rechtssystem] kann nur als

164 gesetzlich wirkliches Anerkennungsleben begriffen werden" ("Anerkennung als Thema in Hegels 'Grundlinien der Philosophie des Rechts", en: Schild, W. (ed.), Anerkennung. Interdisziplinäre Dimensionen eines Begriffs, Wurzburgo: Königshausen \& Neumann, 2000, pp. 41-42, 68 y 70 Reuniendo, en cambio, el reconocimiento de la Fenomenología con el de lo dicho por Wood sobre Hegel respecto a que él "understands it instead as a 'process', beginning with a 'struggle to the death', and passing through an asymmetrical 'master-servant' relation in which one self is recognized by the other without having to recognize the other in turn. In the course of this process, the selves acquire a deeper conception of what is to be a free self, and the rational outcome of the process is the mutual awareness of free self-conscious beings as persons with abstract rights" (Wood, A., Hegel's Ethical Thought, p. 83. Para el desarrollo del argumento, véanse pp. 84-92). 
reconocimiento -y que acompaña ya a su teoría de la propiedad- es compatible y, si sí, si es primaria o más bien derivada, en relación con la argumentación husserliana (sobre todo en la $5^{\mathrm{a}}$. de las Meditaciones cartesianas) que marcha desde el solus ipse a la intersubjetividad trascendental (por empatía o endopatía, Einfühlung, la manifestación del cuerpo propio y los ajenos, el surgimiento del sentido del alter ego, la parificación, etcétera) ${ }^{23}$, o con argumentaciones como las del mencionado González acerca no de reconocimiento ni de espíritu estrictamente objetivo, sino de los actos (y los sentidos) compartidos incluso prelingüisticamente ${ }^{24}$.

VI.

Por último, puede constatarse que en su teoría de la propiedad dentro del derecho abstracto Hegel no trata esas particularidades políticas y económicas de las relaciones humanas con las cosas del tipo qué y cuánto posee alguien ${ }^{25}$. En efecto, por una parte Hegel afirma en el §49 que cuestiones como "qué y cuánto poseo (was und wie viel Ich besitze)" son algo contingente (zufällig)

\footnotetext{
${ }^{23}$ Un buen resumen es el de Serrano de Haro, A., Paseo filosófico en Madrid. Introducción a Husserl, pp. 243-261.

${ }^{24}$ "[Algo interesante hay en] la idea hegeliana de la sociedad como 'espíritu', por más que este espíritu no sea exactamente nunca un espíritu 'objetivo'. Decir que la sociedad es un 'espíritu' es algo que puede entenderse como un modo de recordar que los actos no son cosas, sino el surgir mismo de las cosas. En este sentido, los actos que integran la vida social son 'invisibles', pues no son el término de un surgir, sino el mismo surgir en cuanto tal. En buena medida, la sociedad no es una cosa, sino un surgir de cosas. Y, por eso, precisamente, el núcleo mismo de la sociedad es invisible. Esta invisibilidad es la que permite al individualismo negar que la sociedad sea una realidad, para sostener que solamente hay individuos. Y, ciertamente, desde una perspectiva filosófica, la sociedad no es una mera cosa, ni aparece primeramente como cosa. El núcleo de lo social no es algo que aparece, sino precisamente un aparecer. Pero este aparecer no es algo meramente individual, sino un aparecer compartido. Si el individualismo tiene razón en su oposición a considerar la sociedad como una magna cosa, la crítica al individualismo está acertada al señalar la posibilidad radical y primaria de los actos compartidos, situados en la raíz de todo otro compartir... Este 'espíritu' en que los actos consisten, antes que un espíritu 'objetivo' es un espíritu 'compartido'. Y lo es, precisamente porque los actos humanos... pueden ser compartidos. Aquí es donde cobra su sentido más propio el término filosófico de 'acontecer' como un 'co-tocar'. Más allá del ser social, y más allá de la realidad social, está el acontecer como característica esencial de los actos compartidos... Una comunidad que nos caracteriza radicalmente. Los actos compartidos, precisamente porque son actos, nunca dejan de pertenecer a lo más intimo de nosotros mismos. Los actos no pueden ser un 'espíritu objetivo' porque no pueden ser objetivados. Es posible que se objetive lo que surge en nuestros actos, pero no los actos mismos. Es posible objetivar, por ejemplo, los sistemas de normas, o de significados, o de instituciones, pero no los actos mismos, que siempre permanecen en su radical invisibilidad" (González, A., "Para una 'ontología' de lo social", en: Revista Portuguesa de Filosofia, v. LXXI, 4 (2015), pp. 852-853.

${ }^{25}$ Para más detalles sobre esto, y respecto de los varios límites del derecho abstracto, véase Wood, A., Hegel's Ethical Thought, pp. 101-103 y 106-107.
} 
para el derecho abstracto, que en este terreno la igualdad solo es "la igualdad de la persona abstracta en cuanto tal", y por lo mismo que el problema de la suficiencia de los ingresos para satisfacer necesidades es asunto distinto del de la mera posesión, uno que pertenece a la esfera de la sociedad civil. ¿Por qué? Porque Hegel trata en el derecho solo las bases abstractas y formales de la propiedad, como hemos visto, lo que supone postergar el examen sustancial de la institución de la propiedad para cuando corresponda abordar éticamente a la familia, la sociedad civil y el Estado (con el derecho público). Podría decirse que Hegel hace suyo lo que en teoría jurídica suele denominarse como formalismo e, incluso más, que adopta el peculiar modo de entender el formalismo del derecho privado de un teórico como Weinrib, según el cual la equidad está en la estructura misma de las relaciones de derecho privado entre un demandante y un demandado, tanto así que la justicia correctiva "no involucra ningún juicio sustantivo independiente sobre si una decisión concreta sobre responsabilidad es justa; antes bien, los términos equitativos de la interacción de las partes emergen de un razonamiento que las trate como situadas correlativamente"26. Por lo mismo, agrega Weinrib, "los juicios intuitivos sobre equidad o los juicios sobre la equidad en la distribución total de los recursos en la sociedad están fuera de lugar; los primeros porque no reflejan el contexto del razonamiento, los segundos porque reflejan un contexto erróneo"27.

Sin embargo, se ha dicho que es problemático que este tratamiento hegeliano de la pobreza y la injusticia social, relegado al nivel de la sociedad civil y del Estado, parezca completamente indiferente para la teoría iusprivatista de la propiedad ${ }^{28}$. Obviamente aquí se levanta la crítica marxista de que el individuo titular de los "derechos humanos", especialmente de derechos privados tan paradigmáticos como la propiedad, es el burgués autointere-

\footnotetext{
${ }^{26}$ Weinrib, E., La idea de derecho privado, Páez, E. (trad.), Madrid: Marcial Pons, 2017, p. 17.

27 Ibid. Por otra parte, dice Weinrib, este mismo formalismo no hace ninguna exigencia de uniformidad, como si la justicia correctiva (y su exigencia de coherencia justificativa) que caracteriza la estructura correlativa del derecho privado hubiera de aplicarse uniformemente en todos los sistemas jurídicos. Es todo lo contrario: "precisamente porque la justicia correctiva es general 166 y abstracta, diferentes sistemas de derecho privado pueden manifestarla de diferentes modos. Aunque la justicia correctiva es la construcción teórica estable implícita en cualquier régimen de derecho privado que valore su propia coherencia justificativa y aspire a alcanzarla, puede tener un contenido variable que es relativo a la tradición particular de derecho positivo de una sociedad, a la historia de sus respuestas juridicas ante problemas determinados y a convenciones sociales que se dan en un tiempo y lugar determinados. La justicia correctiva suministra así un modo distintivo de razonamiento moral que permite un contenido variable de sistema a sistema" (Ibid., p. 19).

${ }^{28}$ Véase Mohseni, A., "Eigentum und die soziale Sichtbarkeit der Person" Eigentum, pp. 79-81 (acudiendo a los $\S \S 200,208,238,241,242-249$ de $F D$, entre otros).
} 
sado, desprovisto del vínculo comunitario y desvinculado del interés general ${ }^{29}$. Con todo, es posible defender a Hegel diciendo, como Honneth, que en efecto el derecho privado es abstracto y formal, en el sentido de que en él se trata de individuos singular y equitativamente considerados que requieren de un espacio externo para exteriorizar su voluntad primariamente a través de las cosas: “...según Hegel, el derecho a la propiedad privada encuentra su fundamentación razonable... en el hecho de que le otorga a cada individuo la oportunidad de asegurarse externamente la particularidad de su voluntad en el objeto que le corresponde legitimamente [...Es decir,] en el sistema de los derechos positivos, que constituye la primera institución de la libertad en la modernidad, los sujetos se reconocen como seres libres en la medida en que se atribuyen mutuamente la facultad de poder tomar distancia de todas las determinaciones de la propia voluntad y, por lo tanto, la facultad de prescindir de la vulneración del otro; por consiguiente, existen los unos para los otros solo como personalidades abstractas, que pueden 'abstraerse de todo' y que están en condiciones de respetar las esferas individuales de la libertad de los otros camaradas jurídicos [...El igual derecho individual de disponer de propiedad privada se explica entonces según Hegel asî:] para que su 'libre voluntad' pueda ser una 'voluntad efectiva' al sujeto le debe corresponder un derecho, afianzado y protegido por el Estado, de tener una serie indeterminada de objetos a su exclusiva disposición"30.

Lo que es tanto como suscribir la obviedad de que la perspectiva del derecho privado es necesaria, pero enteramente insuficiente para instituir una exhaustiva teoría de la propiedad. En efecto, la de Hegel es inicialmente una teoría privatista de la propiedad -en el sentido de la típica abstracción del derecho privado. El §46, como se vio, defiende que el derecho a la propiedad privada expresa el derecho de la personalidad, sin que esto excluya la posibilidad de la propiedad común. Pero, por otra parte, la hegeliana no es solamente una teoría privatista de la propiedad. Si la esfera estatal es una esfera jurídica superior y trascendente respecto de los meros intereses particulares, como cree Hegel, entonces en el derecho público se tienen que tratar los rasgos concretos y sustanciales de la propiedad al hilo no solo del individuo

\footnotetext{
${ }^{29} \mathrm{Su}$ locus classicus es Marx, K., "Sobre la cuestión judia”, en: Escritos de juventud sobre el derecho. Textos 1837-1847, Jaramillo, R. (trad.), Barcelona: Anthropos, 2008, pp. 171-204, especialmente pp. 192-197.

${ }^{30}$ A. Honneth, El derecho de la libertad. Esbozo de una eticidad democrática, Calderón, G. (trad.), Madrid/Buenos Aires: Katz Editores, 2014, p. 103. Las cursivas son mías.
} 
sino también de la familia, la sociedad civil y el Estado. En esto consiste el tránsito de lo abstracto a lo concreto -desde la propiedad privadamente regulada hasta la públicamente regulada- que permite arribar, parafraseando la terminología hegeliana, a las cuestiones de quién posee, qué posee, cuánto posee y cómo posee ${ }^{31}$. Y es en este otro momento del tratamiento hegeliano de la propiedad donde emerge la cuestión distributiva. Creo que aquí puede suscribirse la perspectiva de Waldron, para quien la de Hegel es una teoría no individualista sino social de la propiedad -como las llamaba Jhering ${ }^{32}$ que tiene enormes alcances: “...según una aproximación hegeliana, este es el interés básico que cada cual tiene: poseer propiedad contribuye inmensa-

${ }^{31}$ Para rehacer este camino allende, Hegel habria que elaborar una teoria que, considerando las diferencias entre derecho privado y derecho público, permita tratar a la propiedad ante todo como género para después tratar sus especies, la propiedad privada y el dominio público: “...en realidad la propiedad es una institución jurídica anterior a la propiedad privada. Como el propio adjetivo lo sugiere, entre el concepto de propiedad y el de propiedad privada hay una relación de género a especie, por lo que no es correcto definir el género (propiedad) mediante la definición de la especie (propiedad privada)" (Atria, F. y C. Salgado, La propiedad, el dominio público y el régimen de aprovechamiento de aguas en Chile, Santiago de Chile: Thomson Reuters, 2015, p. 5). Propiedad, genéricamente hablando, es un haz de derechos o posiciones jurídicas hohfeldianas que pueden sintetizarse como lo hace Peñailillo: "un señorío monolítico o poder pleno sobre el objeto de la propiedad, con prescindencia de qué facultades identificables puedan describirse separadamente y con autonomia" (citado por Atria y Salgado en ibid., pp. 6-7). Específicamente, propiedad privada es lo que define el artículo 582 del Código civil chileno, esto es, una institución que, como toda institución jurídica, se asienta en el interés general pero "mediado por el interés particular: lo que va en ese caso en el interés general es reconocer al individuo un espacio de autonomía, cuya forma jurídica es el derecho de propiedad privada", mientras que el dominio público es aquella institución en cuya virtud "el interés general se realiza inmediatamente, por la vía de disponer de los bienes del caso para la satisfacción directa de algún aspecto del interés general” (Atria, F. y C. Salgado, ibid., p. 9. Véase, además, pp. 10-59, en donde se desarrolla la noción de bienes nacionales de uso público sobre los cuales sin embargo es admisible bajo ciertas condiciones la constitución de un uso especial privativo, exclusivo y excluyente. Véase también Atria, F., "Sobre el título en la posesión, las cosas al parecer perdidas y la ocupación”, en: Schopf A. y J.C. Marín (eds.), Lo público y lo privado en el Derecho. Estudios en homenaje a Enrique Barros Bourie, Santiago de Chile: Thomson Reuters, 2017, pp. 865-906, aquí pp. 867-869). Para Waldron es fundamental proceder desde la institución de la propiedad en general hasta la distinción entre tipos propietarios (individual, colectivo y común, en sus términos). Para profundizar en esta idea, Véase Waldron, J., The Right to Private Property, pp. 35-53 y 59-60. Esta argumentación -debo este recordatorio a Jorge Larroucau- sigue en parte a Hart, quien, tratando del contenido mínimo del derecho natural y a

168 propósito de los recursos limitados como uno de los hechos básicos de la convivencia humana, decía: "estos hechos por sí solos hacen indispensable alguna forma mínima de la institución de la propiedad (aunque no necesariamente la propiedad individual), y el tipo distintivo de reglas que exigen que se la respete" (Hart, H., El concepto de derecho, Carrió, G. (trad.), Buenos Aires: AbeledoPerrot, 1963, pp. 242-243). La distinción entre la propiedad y sus formas individual, estatal y pública o colectiva remonta a los romanos, como se sabe, y antes que Hart -la teoría analítica anglosajona suele padecer ignorancia histórica- la recordaban Radbruch, G., Filosofia del Derecho, Medina Echavarría, J. (trad.), Madrid: Reus, pp. 242-243, y el mismo Von Jhering, R., El fin en el derecho, Abad, D. y J.L. Monereo (trads.), Granada: Comares, 2011, pp. 222-224.

${ }^{32}$ Von Jhering, R., El fin en el derecho, p. 251. 
mente al desarrollo ético de la persona individual... Lo más interesante de esta aproximación hegeliana es su implicancia distributiva. Si el argumento funciona, establece no solo que la propiedad privada es moralmente legítima, sino también que, en palabras de Hegel, 'cada cual tiene que tener propiedad'. No podemos argumentar, de una parte, que poseer propiedad es necesario para el desarrollo ético, y luego, de otra parte, que es indiferente respecto de la dificultad moral y material de aquellos que nada tienen. Tal como un argumento basado en derechos [a right-based argument] en favor de la libertad de expresión establece un deber de admitir que cada cual puede expresarse libremente, así un argumento basado en un derecho general [general-right-based argument] favorable a la propiedad privada establece un deber de admitir que cada cual tenga que poseer propiedad. Este es en efecto un argumento contra la desigualdad y favorable a la que ha sido llamada 'democracia de posesión de propiedad' ['a property-owning democracy'...] La conclusión importante, entonces, es esta. Bajo un examen serio, no hay ningún argumento basado en derechos que provea una justificación adecuada para una sociedad en la cual algunas personas tengan gran cantidad de propiedad y muchas otras tengan casi ninguna. El eslogan de que la propiedad es un derecho humano solo puede desarrollarse engañosamente para legitimar la desigualdad masiva que encontramos en modernos países capitalistas"33.

Los derechos, por lo demás, como se subordinan al organismo del estado, colisionan y tienen limites, según apunta la Anmerkung al §32. Lo que equivale a decir que la propiedad no es absoluta ni ilimitada, como que en general no hay derechos absolutos ni ilimitados (salvo un peculiar derecho absoluto e ilimitado que Hegel llama "el derecho del espíritu del mundo (das Recht des Weltgeistes)"34. Lo importante es que cada cual tiene que tener propiedad, y no solo la oportunidad de la misma: tal, dice Waldron con razón, es la implicación radical del enfoque hegeliano basado en un derecho general a la propiedad

\footnotetext{
${ }^{33}$ Waldron, J., The Right to Private Property, pp. 3-5; sobre pobreza y desigualdad, véase ibid., pp. 378-386. Contra argumentos utilitaristas basados en premisas agregativas, el de Hegel, dice Waldron, es un peculiar enfoque basado en derechos: "a right-based argument is an argument showing that an individual interest considered in itself is sufficiently important from a moral point of view to justify holding people to be under a duty to promote it" (ibid., p. 3). Este enfoque hegeliano tiene sus dificultades, pero a la vez, y a diferencia del otro enfoque basado en derechos (el de un derecho especial a la propiedad de Locke y Nozick), pretende conectar a la propiedad privada con cosas tales como "individual self-assertion, mutual recognition, the stability of the will, and the establishment of a proper sense of prudence and responsibility" (ibid., p. 4. Veáse pp. 129-130 y su desarrollo detallado en pp. 343-389).

${ }_{34}$ Waldron, J., The Right to Private Property, p. 349.
} 
privada $^{35}$. Honneth marcha en la misma via cuando enfatiza, por una parte, que el tiempo es un ingrediente fundamental de la teoría hegeliana de la propiedad $^{36}$, y cuando, por la otra, insinúa que Hegel quizá no excluya de la misma el que “...por medio de los objetos que ha reunido o a los que tiene un acceso exclusivo, una persona obtiene la oportunidad de someter a una revisión todos los lazos, todas las relaciones y todas las obligaciones que ha entablado en la historia de su vida, puesto que a la luz de los significados existenciales que estas cosas han adquirido con el paso del tiempo, puede explorarse qué clase de vida se quiere llevar. No por otra cosa reivindicaba Virginia Woolf, casi utópicamente, el derecho de toda persona a tener una habitación propia...]"37.

Esto último es algo que recuerda lo que decía Jhering: "en apropiándome la cosa, le imprimo el sello de mi personalidad; cualquier ataque dirigido a ella, me hiere a mí, porque mi propiedad soy yo, como que la propiedad no es más que la periferia de la personalidad extendida a una cosa"38.

$\mathrm{Y}$ que hay una necesidad racional en que yo posea propiedad, como aparece preliminarmente en el derecho abstracto, es algo cuya virtualidad solo se explota después, incluso en otras obras en las que Hegel desarrolla una filosofia no solamente privada sino ya política de la propiedad. Así ocurre en el texto escrito pocos meses antes de su muerte, en 1831, sobre el proyecto de reforma electoral inglés (Über die englische Reformbill), en el que Hegel aplica su teoría social de la propiedad. Dice que la propiedad, como otras instituciones (la del voto y el sistema electoral que lo organiza es solo un ejemplo), puede degenerar, lo que sucede cuando "el interés privado y un sórdido provecho

\footnotetext{
35 Ibid., pp. 408-422 y 439-445. Por cierto, este enfoque hegeliano acerca de la distribución de la propiedad y del derecho a la misma está lejos de lo que pensaba Adam Smith, para quien el derecho perfecto de propiedad se refiere a asuntos de justicia conmutativa regulados legalmente (de maneras crecientemente sofisticadas y frondosas según se avance desde la era de los cazadores, pasando por las eras de los pastores y de la agricultura, hasta la era del comercio), mientras que la cuestión de la distribución sería materia de derechos imperfectos, "aquellos que corresponden a las obligaciones que nos deberian realizar otros, pero de las que no tenemos título para obligarlos a llevarlas a cabo, quedando enteramente en su poder realizarlas o no... No pertenecen [estos derechos imperfectos referidos a la justicia distributiva] propiamente a la jurisprudencia, sino a un sistema moral, pues no caen bajo la jurisdicción de las leyes" (Smith, A., Lecciones sobre jurisprudencia (Curso 1762-3), Escamilla, M. y J.J. Jiménez (trads.), Granada: Comares, 1995, pp. 46-49 y 41-42. Esto muestra la lejanía de Hegel respecto de la posible connivencia entre liberalismo y positivismo metodológico.

${ }^{36}$ Tal como ha dicho Waldron, J., The Right to Private Property, pp. 370ss.

37 Honneth, A., El derecho de la libertad. Esbozo de una eticidad democrática, pp. 104-105.

${ }^{38}$ Von Jhering, R., "La lucha por el derecho", en: Estudios jurídicos, González Posada, A., Buenos Aires: Editorial Heliasta, 1974, p. 40.
} 
pecuniario se han inmiscuido..."39, caso en el cual "tal situación debe ser tratada como precursora de la perdida necesaria de su libertad política, del ocaso de su Constitución y del Estado mismo"40. A diferencia de esa institucionalización políticamente corrupta, un saludable estatuto de la propiedad se basa más bien en el interés general que está allende el provecho o ánimo de lucro, y que supone un permanente trabajo racional dirigido contra el poder fáctico de los privilegios (como los de los propietarios) vigentes solo positivamente ${ }^{41}$. En este sentido, el punto de vista abstracto del derecho privado va "extremadamente en beneficio de la clase que tiene un influjo preponderante en el Parlamento, está relacionada por consiguiente con el Ministerio, que tiene que conferir los altos y más lucrativos cargos eclesiásticos, y tiene interés por sustentar mediante tales prebendas a hijos menores y hermanos..." 42 . La carencia de propiedad (Eigentumslosigkeit) es injustificable, dice Hegel, como lo muestra la miserable clase que vive del trabajo agrícola en Irlanda ${ }^{43}$. Por el contrario, un derecho universal a la propiedad forma parte de "las instituciones de la libertad real", las cuales objetivan el derecho integro de la libertad (das ganze Recht der Freiheit), esto es, el principio -moderno- de que cada cual (jeder) "no se debería dejar determinar por la consideración de lo que otros hacen, sino solo por su propia voluntad, y [de] que su arbitrio individual es lo último, y precisamente lo soberano (seine individuelle Willkür das Letzte und eben das Souveräne ist), que le corresponde y se le reconoce"44. Mientras en Inglaterra la distancia entre la positividad de los privilegios y prejuicios y un derecho más racional y civilizado es casi mayor que "el contraste entre la inmensa riqueza y la pobreza completamente perpleja (der Kontrast von ungeheurem Reichtum und von ganz ratloser Armut)", en Alemania, cree Hegel, se han reformado tranquila pero progresivamente las relaciones jurídicas disminuyéndose los

\footnotetext{
${ }^{39}$ El texto original es Hegel, G.W.F., Über die englische Reformbill. Schriften und Entwürfe II (18261831), en: Hogemann, F. y C. Jamme (eds.), Gesammelte Werke XVI, Hamburgo: Meiner, 2001, p. 332. Uso esta estricta versión castellana: Hegel, G.W.F., Sobre el proyecto de reforma inglés, Maraguat, E. (trad.), Madrid: Marcial Pons, 2005, p. 58. Citaré luego la paginación académica seguida de la de la traducción.

40 Ibid.

${ }^{41}$ Hegel, G.W.F., Über die englische Reformbill, pp. 333-336; Sobre el proyecto de reforma inglés, pp. 59-60.

${ }^{42}$ Hegel, G.W.F., Über die englische Reformbill, pp. 347-348, Sobre el proyecto de reforma inglés, p. 66.

${ }^{43}$ Hegel, G.W.F., Über die englische Reformbill l, pp. 350-354, Sobre el proyecto de reforma inglés, pp. 68-70.

${ }^{44}$ Hegel, G.W.F., Über die englische Reformbill, pp. 390 y 375-376, Sobre el proyecto de reforma inglés, pp. 90 y 82, respectivamente.
} 
privilegios positivos y aumentando el cuerpo del derecho racional, y de una manera tal que aún resulta extraña para el entendimiento inglés (der englische Verstand ${ }^{45}$. Por todo ello, el juicio de Hegel sobre el proyecto británico de reforma electoral, más allá de sus especificidades, enfatiza que la concreta y racional institucionalización de los derechos de la libertad real (die Rechte der reellen Freiheit) es incompatible con el positivismo de los privilegios, como es el de los pocos propietarios ${ }^{46}$.

\section{Conclusiones finales}

Como resumen final, pues, habría que decir que: (i) por su primera, formal y abstracta aparición, la propiedad es la objetivación externa de la voluntad libre mediante la apropiación (común o privada) de cosas exteriores; (ii) por su aparición fenomenológica, la propiedad no solamente mienta todo un mundo dado ya de antemano y al cual está referido el agente de praxis a nativitate, sino también la diferencia absoluta entre personas y cosas así como el problema protoeconómico del acceso (sea del tipo que sea) de aquellas a estas mediante actos y distintas configuraciones de los mismos; (iii) por su estatuto ontológico y normativo, la propiedad que es racionalmente necesaria para la libre personalidad supone (y se manifiesta a través de) el reconocimiento -o respeto- de las autoconciencias tanto en su fase más abstracta como en sus configuraciones éticas más concretas, y esto aun cuando la noción de reconocimiento y de espíritu objetivo sean construcciones algo pesadas y mejorables con una detalladísima analítica descriptiva -tanto filosófica como empírica- sea de la endopatía que permite el surgimiento del otro y que constituye la intersubjetividad, sea de los actos compartidos y la intencionalidad conjunta y a la vez colectiva apreciable en niveles ontogenéticos incluso prelingüísticos y en su posterior desarrollo en sistemas de normas e instituciones; y (iv) por esta su cara politica y especialmente distributiva, la propiedad no rechaza el formalismo típico del derecho privado en tanto que asentado en relaciones de justicia correctiva, pero también exige -en vistas de la libertad real-la concreta universalidad del derecho público, de modo tal que incluso la necesidad racional de la propiedad privada sea realizada mediante un acceso a la misma por parte de todos y cada cual (abominando por ende de los privilegios y demás positividades no racionalizables), lo que es

\footnotetext{
${ }^{45}$ Hegel, G.W.F., Über die englische Reformbill, pp. 390-391; Sobre el proyecto de reforma inglés, pp. 89-90.

${ }_{46}$ Hegel, G.W.F., Über die englische Reformbill, pp. 399-404; Sobre el proyecto de reforma inglés, pp. 93-95.
} 
tanto como decir que la propiedad debe ser organizada y distribuida universalmente a través de mecanismos institucionales y estatales ${ }^{47}$.

Recibido: 25/02/2020

Aceptado: 11/08/2020

\section{Bibliografia}

Amengual, G., La moral como derecho. Estudio sobre la moralidad en la Filosofia del Derecho de Hegel, Madrid; Trotta, 2001.

Atria, F., "Sobre el título en la posesión, las cosas al parecer perdidas y la ocupación", en: Schopf, A. y J.C. Marín (eds.), Lo público y lo privado en el Derecho. Estudios en homenaje a Enrique Barros Bourie, Santiago de Chile: Thomson Reuters, 2017, pp. 865-906.

Atria, F. y C. Salgado, La propiedad, el dominio público y el régimen de aprovechamiento de aguas en Chile, Santiago de Chile: Thomson Reuters, 2015.

Bourgeois, B., Le droit naturel de Hegel (1802-1803). Commentaire, París: Vrin, 1986. Cordua, C., Explicación sucinta de la Filosofia del Derecho de Hegel, Bogotá: Temis, 1992. Cordua, C., "El cuerpo propio", en: Estudios sobre Hegel, Santiago de Chile: Ediciones UDP, 2019, pp. 45-54.

Eyssidieux-Vaissermann, A., "La refondation du droit naturel moderne", en : Kervégan, J.-F. y G. Marmasse (eds.), Hegel penseur du droit, París : CNRS Éditions, 2004, pp. 47-62. https://doi.org/10.4000/books.editionscnrs.6006

González, A., Estructuras de la praxis. Ensayo de una filosofia primera, Madrid: Trotta, 1997.

\footnotetext{
${ }^{47}$ Otra forma de resumir las ideas hegelianas, no muy atenta a las cuestiones fenomenológicas ni político-distributivas, es la de Rawls, J. Lecciones sobre la historia de la filosofia moral, De Francisco, A. (trad.), Barcelona: Paidós, 2007, quien, combinando los $\$ \S 10$ y 27 de FD, trata de explicar qué quiere decir que "la voluntad libre es la voluntad que se quiere a sí misma como voluntad libre" (ibid., p. 405). Si la misma Sittlichkeit es entendida como "un sistema de instituciones políticas y sociales que expresa y actualiza en el mundo el concepto de libertad" (ibid., p. 428), entonces -según Rawls- la voluntad libre quiere un tal sistema institucional, de formas de vida humana que educan a la voluntad libre y cuyos fines ha de poder querer esa voluntad libre (ibid., pp. 427-428). Ahora bien, la propiedad privada plantea esta cuestión: “¿cómo se conforma el sistema de sus derechos con los dos imperativos de 'ser una persona y respetar los derechos de los demás como personas; y no violar la personalidad y lo que ella encierra'? ¿Cómo exactamente muestran los derechos de propiedad -a poseerla, usarla e incluso abusar de ella; a privar de ella a los demás así como a venderla- respeto por las personas y encarnan el concepto de voluntad libre?" (ibid., pp. 417-418). La respuesta de Hegel es que puede entenderse el derecho de propiedad privada como uno que expresa la libertad de la voluntad (p. 428). La teoría hegeliana de la propiedad no es utilitarista ni psicologista, asegura Rawls, sino - sit venia verbo- expresivista: un sistema de la propiedad "ha de expresar la libertad" (ibid., p. 420), es "la encarnación más adecuada de la libertad" (ibid., p. 419; véase pp. 417-420).
} 
González, A., Surgimiento. Hacia una ontología de la praxis, Bogotá: Universidad Santo Tomás, 2014.

González, A., "Para una 'ontologia' de lo social”, en: Revista Portuguesa de Filosofia, v. LXXI, 4 (2015), pp. 833-854. https://doi.org/10.17990/rpf/2015_71_4_0833

Gottschlich, M., "Enseñando a hablar inglés a la filosofia hegeliana. Entrevista a Stephen Houlgate", Abramovich, L. (trad.), en: Ideas y valores, LXVI, 165 (2017), pp. 373-411.

Hart, H., El concepto de derecho, Carrió G., (trad.), Buenos Aires: Abeledo-Perrot, 1963.

Hegel, G.W.F., Principios de la filosofía del derecho, Vermal, J.L. (trad.), Barcelona: Edhasa, 1988.

Hegel, G.W.F., Rasgos fundamentales de la filosofia del derecho o compendio de derecho natural y ciencia del estado, Vásquez, E. (trad.), Madrid: Biblioteca Nueva, 2000.

Hegel, G.W.F., Schriften und Entwürfe II (1826-1831). Über die englische Reformbill, en: Hogemann, F. y C. Jamme (eds.), Gesammelte Werke XVI, Hamburgo: Meiner, 2001. https://doi.org/10.28937/978-3-7873-3398-1

Hegel, G.W.F., Sobre el proyecto de reforma inglés, Maraguat, E. (trad.), Madrid: Marcial Pons, 2005.

Hegel, G.W.F., Naturrecht und Staatswissenschaft im Grundrisse. Grundlinien der Philosophie des Rechts, Grotsch, en: K. y E. Weisser-Lohmann (eds.), Gesammelte Werke XIV, Hamburgo: Meiner, 2009. https://doi.org/10.28937/978-3-7873-3395-0

Hegel, G.W.F., Fundamentos de la Filosofia del Derecho o Compendio de Derecho Natural y Ciencia Política, Abellán, J. (trad.), Madrid: Tecnos, 2017.

Hegel, G.W.F., Lineas fundamentales de la filosofía del derecho, en: Hegel II, Paredes, M. del C. (trad.), Madrid: Gredos, 2010, pp. 9-312.

Herzog, L., "Hegel als Denker des Marktes", en: Siep, L., G.W.F. Hegel. Grundlinien der Philosophie des Rechts, pp. 209-224. https:/ / doi.org/10.1515/9783110496529-014

Honneth, A., El derecho de la libertad. Esbozo de una eticidad democrática, Calderón, G. (trad.), Madrid/Buenos Aires: Katz editores, 2014.

Houlgate, S., "Property, Use and Value in Hegel's Philosophy of Right", en: James, D., Hegel's Elements of the Philosophy of Right. A Critical Guide, pp. 37-57. https:// doi.org/10.1017/9781139939560.003

Ilting, K.-H., "La estructura de la 'Filosofia del Derecho' de Hegel”, en: Amengual, G. (ed.), Estudios, pp. 67-92.

Marx, K., "Sobre la cuestión judía", en: Escritos de juventud sobre el derecho. Textos 1837-1847, Jaramillo, R. (trad.), Barcelona: Anthropos, 2008.

Mohseni, A., "Eigentum und die soziale Sichtbarkeit der Person", en: Siep, L. (ed.), G.W.F. Hegel. Grundlinien der Philosophie des Rechts, Berlin/Boston : Walter de Gruyter, 2017, pp. 61-82. https://doi.org/10.1515/9783110496529-007

Radbruch, G., Filosofia del Derecho, Medina Echavarría, J. (trad.), Madrid: Reus.

Rawls, J., Lecciones sobre la historia de la filosofia moral, De Francisco, A. (trad.), Barcelona: Paidós, 2007. 
Ritter, J., "Persona y propiedad. Un comentario de los §§34-81 de los 'Principios de la Filosofia del Derecho' de Hegel”, en: Amengual, G. (ed.), Estudios sobre la 'Filosofia del Derecho' de Hegel, Madrid: CEC, 1989, pp. 121-142.

Schild, W., "Anerkennung als Thema in Hegels 'Grundlinien der Philosophie des Rechts", en: Schild, W. (ed.), Anerkennung. Interdisziplinäre Dimensionen eines Begriffs, Wurzburgo: Königshausen \& Neumann, 2000, pp. 37-72.

Serrano de Haro, A., Paseo filosófico en Madrid. Introducción a Husserl, Madrid: Trotta, 2016.

Siep, L., "Intersubjektivität, Recht und Staat in Hegels Grundlinien der Philosophie des Rechts", en : Henrich, D. y R. P. Horstmann (eds.), Hegels Philosophie des Rechts. Die Theorie der Rechtsformen und ihre Logik, Stuttgart, 1984.

Smith, A., Lecciones sobre jurisprudencia (Curso 1762-3), Escamilla, M. y J.J. Jiménez (trads.), Granada: Comares, 1995.

Valls Plana, R., Comentario integral a la Enciclopedia de las ciencias filosóficas de G.W.F. Hegel (1830), Madrid: Abada, 2018.

Vieweg, K., Das Denken der Freiheit. Hegels Grundlinien der Philosophie des Rechts, Paderborn: Wilhelm Fink, 2012. https://doi.org/10.30965/9783846753040

Von Jhering, R., "La lucha por el derecho", en: Estudios jurídicos, González Posada, A. (trad.), Buenos Aires: Editorial Heliasta, 1974.

Von Jhering, R., El fin en el derecho, Abad, D. y J.L. Monereo (trads.), Granada: Comares, 2011.

Waldron, J., The Right to Private Property, Oxford: Oxford University Press, 1988.

Weinrib, E., La idea de derecho privado, Páez, E. (trad.), Madrid: Marcial Pons, 2017.

Wood, A., Hegel's Ethical Thought, Cambridge: Cambridge University Press, 1990.

Xifaras, M., "L’individualisme possessif, spéculatif (et néanmoins romain) de Hegel. Quelques remarques sur la théorie hégélienne de la propriété”, en : Kervégan, J.-F. y G. Marmasse (eds.), Hegel penseur du droit, París : CNRS Éditions. 